\title{
Evolution characters of water exchange abilities between Dongting Lake and Yangtze River
}

\author{
OU Chaomin ${ }^{1}$, LI Jingbao², ZHOU Yongqiang ${ }^{3,4}$, CHENG Weiyan², YANG Yan², \\ ZHAO Zhonghua ${ }^{2}$ \\ 1. College of Information System and Management, National University of Defense Technology, Changsha \\ 410073, China; \\ 2. College of Resources and Environmental Sciences, Hunan Normal University, Changsha 410081, China; \\ 3. Nanjing Institute of Geography and Limnology, CAS, Nanjing 210008, China; \\ 4. University of Chinese Academy of Sciences, Beijing 100049, China
}

\begin{abstract}
By using field-survey hydrological data of the related control stations in Dongting Lake and the Yangtze River mainstream in 1951-2010, the evolution characters of water exchange abilities between the two water bodies and their response to the operation of the Three Gorges Reservoir (TGR) from different time scales are analyzed based on their hydraulic relations. The results are shown as follows. Firstly, during July-September, the replenishment ability of Three Outlets to Dongting Lake is stronger, and in January-March, the replenishment ability of Dongting Lake to Yangtze River is stronger. Secondly, there has been an obvious inter-decadal wave on the water exchange coefficient between Dongting Lake and Yangtze River. In 1951-1958 and 1959-1968, the replenishment ability of Three Outlets to Dongting Lake was stronger, but in 2003-2010, the replenishment ability of Dongting Lake to Yangtze River has been strengthened. Thirdly, the spill-division ability of Three Outlets weakens, and the water of Dongting Lake coming from Three Outlets decreases either in typical years or under different dispatching modes of the TGR after the operation of the Three Gorges Reservoir. Furthermore, the water of Dongting Lake coming from Four Rivers takes the dominant position, which obviously enhances the replenishment ability of Dongting Lake to Yangtze River. Fourthly, if the effect of the runoff fluctuation in the basin is not considered, the evolution characters of the exchange capacities and the exchange process between Dongting Lake and Yangtze River in different time scales are generally changed with the variation of the water exchange amount between them, although the factors influencing the water exchange capacities between them is very complex. These show that there is an in-line growth or decline relation between the river-lake water exchange ability and the river-lake water exchange amount.
\end{abstract}

Keywords: water exchange coefficient; evolution of water exchange function; Dongting Lake; Yangtze River

Received: 2013-08-13 Accepted: 2013-09-12

Foundation: National Natural Science Foundation of China, No.41071067; Construct Program of the Key Discipline of the Physical Geography in Hunan Province

Author: Ou Chaomin (1979-), $\mathrm{PhD}$ and Associate Professor, specialized in disaster and emergency management. E-mail: ouchm@163.com 


\section{Introduction}

Jingjiang from Zhicheng to Chenglingji in the Yangtze River mainstream is not only the ties connecting the middle-lower Yangtze River and the Three Gorges Reservoir (TGR) but also the current pass linking Dongting Lake. There is a close relation between Yangtze River and Dongting Lake (the river-lake relation), which has a long history. From 1951 to 2002, the river-lake relation has changed and adjusted several times with the blocking of Tiaoxiankou, the Jingjiang truncation and the river closure of Gezhouba, etc., which influences the resource and environment of the middle Yangtze River and Dongting Lake to a certain extent (Qu et al., 2007; Zhang et al., 2012; Li et al., 2013). Obviously, the change in the river-lake relation is a key science question related with the administration, exploitation and protection of Yangtze River and Dongting Lake (Betts et al., 2008; Zhang et al., 2011). So it has been paid great attention all along. The river-lake relation has been studied by the scholars from different angles (Mikhailov et al, 2001; Zhong and Hu, 2008; Sun et al., 2012). However, all these achievements did not deal with the evolution characters of water exchange abilities between Dongting Lake and Yangtze River (river-lake water exchange abilities). On the other hand, the TGR began to store water in June of 2003, which means the river-lake relation has entered into a new variational and adjustive process. In a word, the evolution characters of river-lake water exchange abilities and its response to the operation of the TGR in recent 60 years are comprehensively analyzed based on the field-survey prototype runoff series. This is very important to scientifically understand the river-lake relation, improve the linking function of the river-lake water system and maintain the health of Yangtze River and Dongting Lake.

\section{Data and research method}

\subsection{Hydrology data}

The flow and sediment from Three Outlets ${ }^{1}$ in the south bank of Jingjiang in the middle Yangtze River and from Four Rivers ${ }^{2}$ in Hunan Province enter Dongting Lake, which enter Yangtze River at Chenglingji after the adjustment of the lake. This forms a complex river-lake hydraulic relation (Figure 1). Based on the hydrological relation among the TGR, Three Outlets, Four Rivers and Chenglingji, the following data will be used: the annual runoff and the multi-year monthly average runoff in 1951-2010 of Xinjiangkou Station, Shadaoguan Station, Mituosi Station, Kangjiagang Station, Guanjiapu Station, Xiangtan Station, Taojiang Station, Taoyuan Station, Shimen Station, Chenglingji Station and Zhicheng Station; the monthly average outflow water volume from the TGR under different dispatching modes in 2003-2010. The daily average discharge volume and the monthly average runoff of the TGR in 2003-2010 are obtained from the water regimes in the website of China Three Gorges Corporation. The monthly and annual runoffs of all control stations in the Dongting Lake area are got from the daily regimes report table on the website of Hunan Survey Bureau of Hydrology and Water Resources. The monthly average runoff, the monthly average water level and the annual runoff in 1951-2002 are provided by Hunan Hydro\&Power De-

\footnotetext{
1 Three Outlets include Songzikou, Ouchikou and Taipingkou.

${ }^{2}$ Four Rivers refer to Xiangjiang River, Zijiang River, Yuanjiang River and Lishui River.
} 


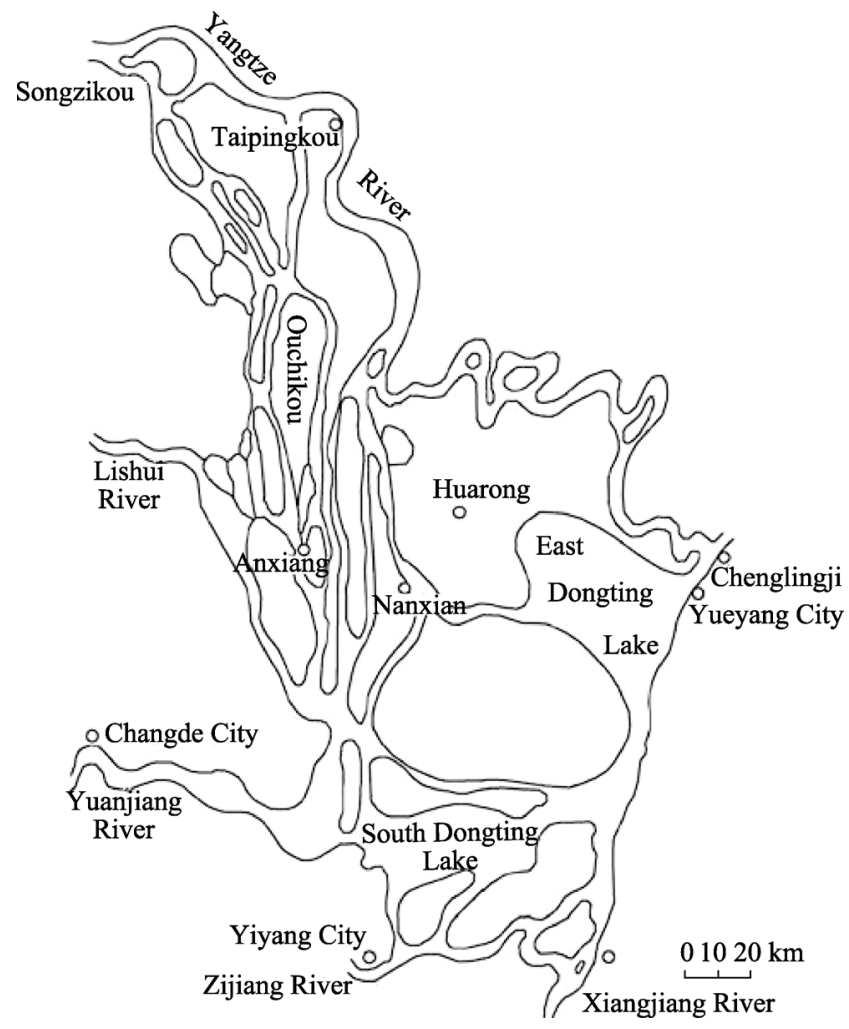

Figure 1 The Dongting Lake area

sign Institute and from hydrology yearbooks of the Dongting Lake area from 1951 to 1983.

\subsection{Analysis method of water exchange abilities between Yangtze River and Dongting Lake}

Compared to Poyang Lake reaching Yangtze River, Dongting Lake has greater water exchange abilities, i.e. more thruput, and different water exchange forms (Guo and Zhang, 2011). Water exchange abilities between Yangtze River and Dongting Lake are shown in two aspects: one is the water volume of Three Outlets from Yangtze River, i.e. the replenishment ability of Yangtze River to Dongting Lake. Generally, if the water volume from Three Outlets is large, the water level of Dongting Lake will increase; the other is the water volume of Chenglingji from Dongting Lake, i.e. the replenishment ability of Dongting Lake to Yangtze River. Generally, if the water volume from Chenglingji is big, the water volume of the middle Yangtze River will increase. According to this relation, water exchange abilities between Yangtze River and Dongting Lake are shown by the ratio of the water volume from Three Outlets to the water volume from Chenglingji per unit time. The water exchange coefficient between Yangtze River and Dongting Lake is used to measure water exchange abilities to facilitate quantitative analysis. Water exchange coefficient between Yangtze River and Dongting Lake $(I)$ is calculated as follows:

$$
I=\frac{R_{i} \times R_{a o}}{R_{o} \times R_{a i}}
$$


where $R_{i}$ represents the water volume from Three Outlets in $i$ year, $R_{o}$ represents the water volume from Chenglingji in $o$ year, $R_{a i}$ represents the multi-year average runoff from Three Outlets, and $R_{a o}$ represents the multi-year average runoff from Chenglingji. According to equation (1), when $I=1$, water volumes from Three Outlets and Chenglingji are in balance, i.e., water exchange abilities are relatively stable; when $I>1$, the replenishment ability of Three Outlets to Dongting Lake is stronger. What's more, the greater the $I$ is, the stronger the ability is; when $I<1$, the replenishment ability of Dongting Lake to Yangtze River is stronger. What's more, the greater the $I$ is, the stronger the ability is. So the water exchange ability between Yangtze River and Dongting Lake is a relative value.

\subsection{Definitions of the research time scale}

The water exchange ability and amount between Yangtze River and Dongting Lake both have the nature of randomness. So, in order to comprehensively reveal the evolution characters of river-lake water exchange abilities in recent 60 years, different research time scales are defined as follows:

(1) The annual runoff series in 1951-2010 is divided into 6 periods: 1951-1958 (before the blocking of Tiaoxiankou), 1959-1968 (before the Jingjiang truncation and after the blocking of Tiaoxiankou), 1969-1972 (during the Jingjiang truncation), 1973-1980 (before the river closure of Gezhouba and after the Jingjiang truncation), 1981-2002 (before the water storage of the TGR and after the river closure of Gezhouba), and 2003-2010 (after the water storage of the TGR).

(2) The typical year is defined based on the annual runoff series. The runoff frequency analysis cannot be used because the data series is short. So, the typical hydrological year is defined according to the standard of dividing the wet or the dry runoff used in the hydrological forecast criterion of the information center of the Ministry of Water Resources of the People's Republic of China. The standard is represented as follows:

$$
P=\frac{\text { the runoff in } \mathrm{t}^{\text {th }} \text { year }- \text { the average runoff }}{\text { the average runoff }} * 100 \%
$$

The year is $\left\{\begin{array}{l}\text { the wet year, if } P>20 \% \\ \text { the normal year, if }-10 \%<P \leqslant 10 \% \\ \text { the dry year, if } P<-20 \%\end{array}\right.$

Based on this standard (Hu, 2000), 2006, 2007 and 2010 are respectively the dry year, the normal year and the wet year after the running of the TGR. According to the frequency analysis of the annual runoff series in 1951-2002 of Zhicheng Station and Chenglingji Station, 1994, 1960 and 1990 are respectively the dry year, the normal year and the wet year before the operation of the TGR based on equation (2) (Table 1).

(3) The biggest acceleration of the water volume from Four Rivers in the Dongting Lake area is from April to June. The biggest water volume of the upper-middle Yangtze River is from July to September. It is in dry seasons or in low water level seasons from January to March. So, the intra-annual change of water exchange abilities between Yangtze River and Dongting Lake from April to June, from July to September and from January to March is respectively analyzed. 
Table 1 Comparison between the water volumes of Three Outlets and Chenglingji under similar water volume of Zhicheng Station before and after the operation of the TGR

\begin{tabular}{cccccccccc}
\hline Year & $\begin{array}{c}\text { Runoff of } \\
\text { Zhicheng } \\
\text { Station } \\
\left(10^{8} \mathrm{~m}^{3}\right)\end{array}$ & $\begin{array}{c}\text { Anomalies } \\
\text { of the } \\
\text { runoff }(\%)\end{array}$ & $\begin{array}{c}\text { Water } \\
\text { volume } \\
\text { of Three } \\
\text { Outlets } \\
\left(10^{8} \mathrm{~m}^{3}\right)\end{array}$ & $\begin{array}{c}\text { Water } \\
\text { volume of } \\
\text { Chenglingji } \\
\left(10^{8} \mathrm{~m}^{3}\right)\end{array}$ & $\begin{array}{c}\text { Year } \\
\text { Runoff of } \\
\text { Zhicheng } \\
\text { Station } \\
\left(10^{8} \mathrm{~m}^{3}\right)\end{array}$ & $\begin{array}{c}\text { Anomalies } \\
\text { of the } \\
\text { runoff }(\%)\end{array}$ & $\begin{array}{c}\text { Water } \\
\text { volume of } \\
\text { Three } \\
\text { Outlets } \\
\left(10^{8} \mathrm{~m}^{3}\right)\end{array}$ & $\begin{array}{c}\text { Water } \\
\text { volume of } \\
\text { Chenglingji } \\
\left(10^{8} \mathrm{~m}^{3}\right)\end{array}$ \\
\hline 1976 & 4246.8 & +0.6 & 586.7 & 2861.1 & 2003 & 4229.7 & +1.8 & 576.2 & 2684.5 \\
1995 & 4216.5 & -0.1 & 500.8 & 2321.2 & 2004 & 4217.5 & +1.5 & 532.7 & 2327.4 \\
1951 & 4556.0 & +7.9 & 1480.0 & 3098.0 & 2005 & 4542.1 & +9.3 & 632.2 & 2415.2 \\
1994 & 3432.6 & -18.7 & 344.9 & 2738.0 & 2006 & 2930.6 & -29.5 & 184.6 & 1989.6 \\
1960 & 4192.1 & -0.7 & 634.2 & 2824.6 & 2007 & 4180.3 & +0.6 & 550.4 & 2093.5 \\
1996 & 4263.7 & +1.0 & 763.2 & 2549.9 & 2008 & 4276.5 & +2.9 & 536.5 & 2253.6 \\
1971 & 4045.5 & -4.2 & 819.3 & 2320.9 & 2009 & 4043.0 & -2.7 & 449.0 & 2020.0 \\
1999 & 4823.9 & +14.3 & 808.8 & 2990.6 & 2010 & 4824.0 & +16.1 & 632.4 & 2765.0 \\
\hline
\end{tabular}

(4) According to "the Management Scheme of the Three Gorges Reservoir", there are four types of dispatching modes, i.e. the pre-discharge dispatch (from 25 May to 10 June), the flood-storage dispatch (from 1 July to 31 August), the water-storage dispatch (from 15 September to 31 October) and the water-supplement dispatch (from January to March or from December to April in the next year). This will facilitate to analyze the effect of different dispatching modes of the TGR on water exchange abilities between Yangtze River and Dongting Lake in corresponding periods in typical years.

\section{The hydraulic-relation degree between Yangtze River and Dongting Lake}

Dongting Lake is a large lake reaching rivers and has close hydraulic relations with rivers. Two steps are taken to verify the hydraulic-relation degree between Yangtze River and Dongting Lake. Firstly, the correlation graph between monthly runoffs of Zhicheng Station and Three Outlets (Figure 2) and the correlation graph between monthly runoffs of Three Outlets and Chenglingji (Figure 3) are plotted with points using the monthly average runoffs of Zhicheng Station, Three Outlets and Chenglingji in 1951-2010. The figures show the correlations between monthly runoffs of Zhicheng Station and Three Outlets, and between monthly runoffs of Three Outlets and Chenglingji are both positive and very significant $(p<$ 0.0001 ). The values of their $r^{2}$ respectively equal 0.867 and 0.592 , which indicates there is a very close relation between runoffs of Yangtze River and Dongting Lake. Secondly, the field-survey monthly average water levels of Zhicheng Station, Luoshan Station and Chenglingji Station in 1951-2010 are calculated to explore the correlations between monthly average water levels of Chenglingji Station and Zhicheng Station, and between monthly average water levels of Chenglingji Station and Luoshan Station. The values of their $r^{2}$ respectively equal 0.926 and $0.999^{3}$, which shows there is also a very significant

\footnotetext{
${ }^{3}$ China Institute of Water Resources and Hydropower Research and Department of Water Resources of Hunan Province. "Research on Rational Allocation of Water Resources in the Dongting Lake Area". Research Report, $2011,10$.
} 
linear relation between water levels of Yangtze River and Dongting Lake. This also shows: The water-level of Dongting Lake is influenced by the backwater of Yangtze River to a certain extent, and its change is basically consistent with the water-level change of the upper Jingjiang; At the same time, the water-level of Luoshan Station in Yangtze River is influenced by the water level of Chenglingji Station, and its change is basically consistent with the water-level change of Chenglingji.

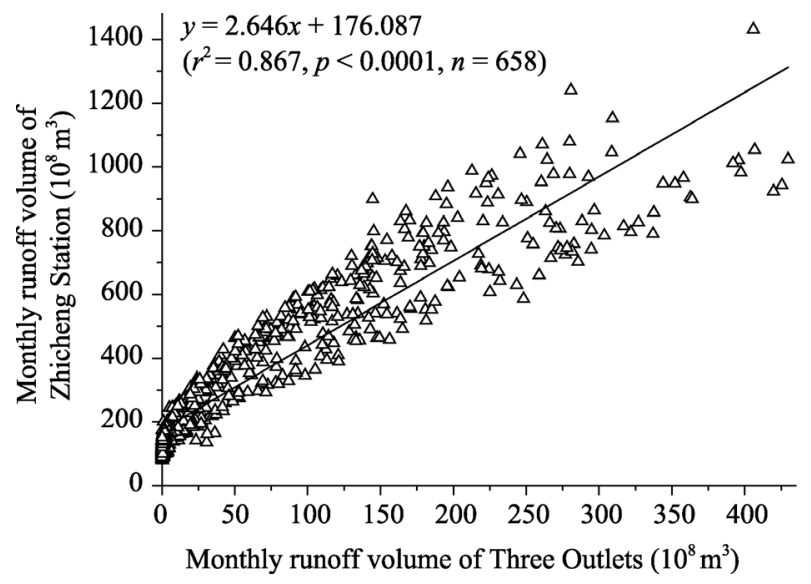

Figure 2 The correlation between monthly runoffs of Three Outlets and Chenglingji

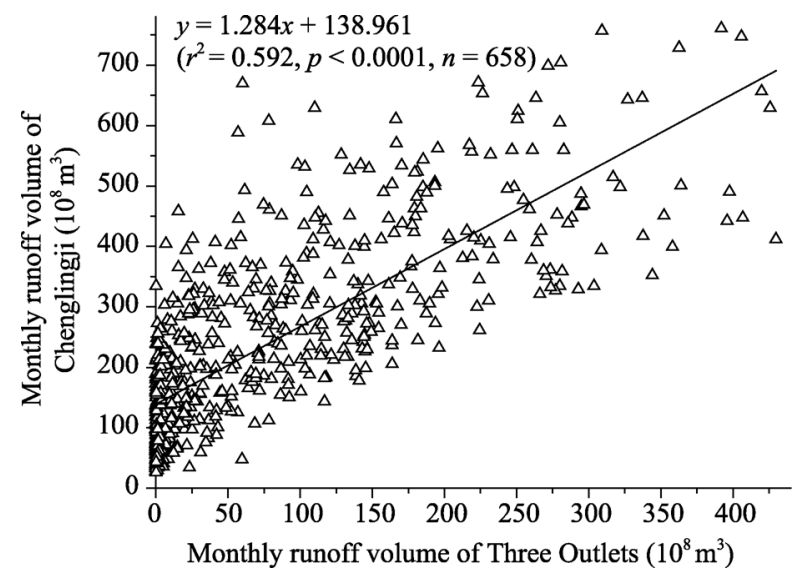

Figure 3 The correlation between monthly runoffs of Zhicheng Station and Three Outlets

\section{Evolution of river-lake water exchange abilities}

The intensity of water exchange abilities between Yangtze River and Dongting Lake are shown through the replenishment process of Three Outlets to Dongting Lake and the replenishment process of Dongting Lake to Yangtze River. This process and intensity change with the intra- and inter-annual change of the water level and the water volume under the unstable climate and the disturbance of the hydraulic project's operation in different periods. Obviously, there is a clear time-scale character with water exchange abilities and amounts between Yangtze River and Dongting Lake. 


\subsection{Seasonal changes of river-lake water exchange abilities}

The multi-year monthly average water exchange coefficients between Yangtze River and Dongting Lake are calculated (Table 2) based on the multi-year monthly average runoffs of Three Outlets, Four Rivers and Chenglingji in 1951-2010. According to Table 2, spring is low water level periods or dry seasons of Yangtze River and Dongting Lake, and water exchange coefficients between Yangtze River and Dongting Lake are the minimum throughout the year, i.e. it is the season when both the replenishment amount of Three Outlets to Dongting Lake and the replenishment amount of Dongting Lake to Yangtze River are the minimum. However, the replenishment ability of Dongting Lake to Yangtze River is stronger because there is much water from Four Rivers. In summer, the water volume of Three Outlets gradually increases and the replenishment ability of Three Outlets to Dongting Lake correspondingly improves. The water volume of Four Rivers is the maximum throughout the year for main flood seasons of Four Rivers. This exchange process is not only helpful to weaken peak flood of the upper-middle Four Rivers but also does not cause threats of the flood to the Dongting Lake area. Autumn is the main flood season of the Yangtze River and the replenishment ability of Three Outlets to Dongting Lake improves, i.e. the water volumes of both Three Outlets and Chenglingji are the maximum throughout the year. So the river-lake water exchange coefficient is the biggest throughout the year. This process is helpful to relieve the flood pressure in the middle-lower Yangtze River region because the main flood seasons of Four Rivers are over in autumn. However, if the main flood seasons of Four Rivers prolong, the flood from Yangtze River and from Four Rivers encounter in Dongting Lake, which will increase the probability of the flood in the lake area. Therefore, from both the perspective of flood regulation and disaster reduction, and the perspective of water resources development and utilization, Dongting Lake plays a big role in flood storage and disaster reduction of the Yangtze River and Four Rivers in summer and autumn every year in recent 60 years, and Dongting Lake has also contributed much to replenishing water resources to the middle-lower Yangtze River region in spring.

Table 2 Quarterly average runoffs $\left(10^{8} \mathrm{~m}^{3}\right)$ of the Donting Lake and exchange coefficients over years

\begin{tabular}{cccccc}
\hline Season & $\begin{array}{c}\text { Runoff of Three } \\
\text { Outlets }\end{array}$ & $\begin{array}{c}\text { Runoff of Four } \\
\text { Rivers }\end{array}$ & $\begin{array}{c}\text { Runoff of inflow } \\
\text { into the Lake }\end{array}$ & $\begin{array}{c}\text { Runoff of } \\
\text { Chenglingji }\end{array}$ & $\begin{array}{c}\text { Exchange coef- } \\
\text { ficient (I) }\end{array}$ \\
\hline Spring & 1.27 & 86.23 & 87.50 & 102.57 & 0.04 \\
Summer & 50.80 & 250.63 & 301.43 & 316.87 & 0.48 \\
Autumn & 195.63 & 146.00 & 341.63 & 392.00 & 1.66 \\
Winter & 42.90 & 69.90 & 112.80 & 154.33 & 0.61 \\
\hline
\end{tabular}

\subsection{Inter-annual changes of river-lake water exchange abilities}

The water exchange coefficient between Yangtze River and Dongting Lake is calculated based on equation (1). During its evolution process in 1951-2010, the coefficient tends to decrease as a whole and there is an obvious inter-annual fluctuation (Figure 4). Its changing trend is closely related with the inter-annual change of precipitation in the middle Yangtze River region (Guo and Zhang, 2011), the inter-annual change of precipitation in the Dong- 
ting Lake area (Figure 5), the runoff change of Three Outlets and the runoff change of Chenglingji.

What's more, its changing trend is obviously consistent with the change of the runoff of Three Outlets. This indicates the inter-annual change of the river-lake water exchange ability changes according to the inter-annual variation of precipitation in the basin, the Three

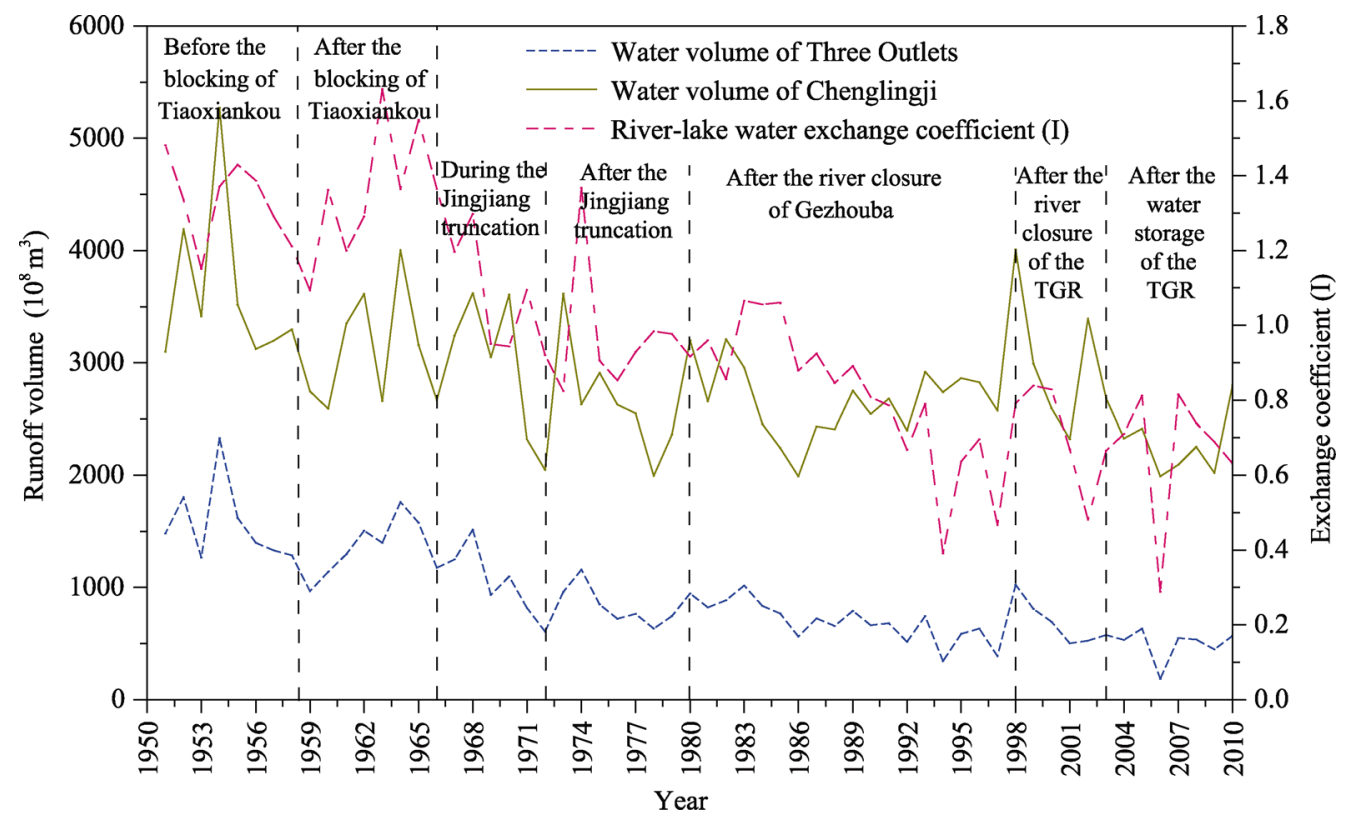

Figure 4 Variation of the water exchange coefficient between Dongting Lake and Yangtze River in the past 60 years

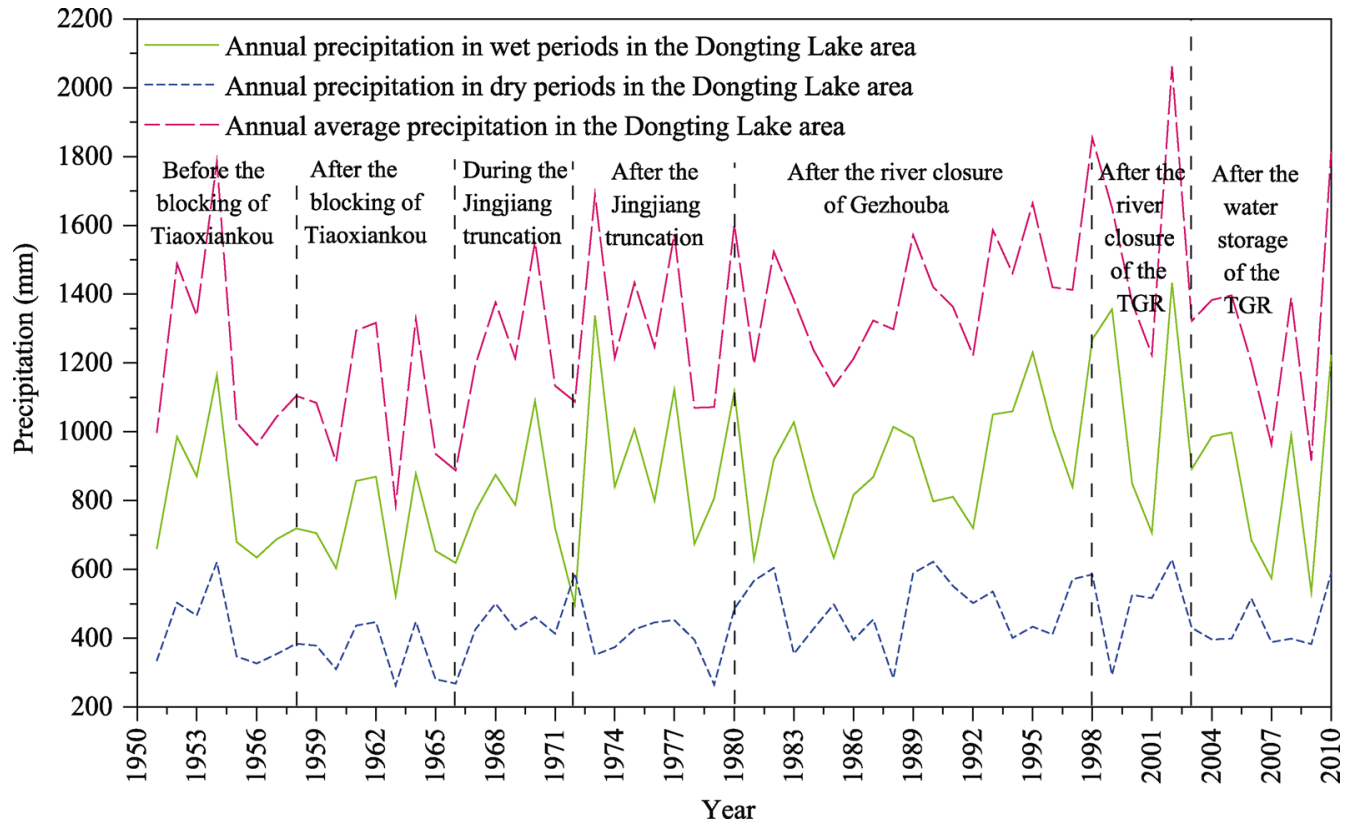

Figure 5 The process line of the annual average precipitation in the Dongting Lake area 
Outlet's runoff and the Chenglingji's runoff. During this process, the river-lake water exchange coefficient respectively reached two high values in 1951-1958 and in 1959-1968. During these periods, the water volume of Three Outlets was sufficient, i.e. the replenishment ability of Three Outlets to Dongting Lake was stronger. The coefficient decreased in 1969-1972. The reasons are as follows: Jingjiang was truncated during this period; the discharge volume of Zhicheng increased and the water volume of Three Outlets decreased. The value fluctuation of the river-lake water exchange coefficient was small in 1981-2002, which indicates the river-lake water exchange ability was relatively stable during this period. There are two reasons: One is that the operation of Gezhouba in 1981 did not produce profound effects on the river-lake relation ( $\mathrm{Li}$ and Liu, 1993); The other is that the change extent of the river-lake water exchange amount is relatively stable because the sediment scouring and deposition of the riverbed is in relative balance after the multi-year natural regulation of the riverbed ( $\mathrm{Lu}$ and Luo, 1999). The TGR stored water in 2003-2010 and the river-lake water exchange coefficient was the minimum in the history, i.e. the replenishment ability of Three Outlets to Dongting Lake was the weakest and the replenishment ability of Dongting Lake to Yangtze River was the strongest. Besides the annual precipitation in the upper-middle Yangtze River region and in the Dongting Lake Basin is less compared with the precipitation in normal years, this evolution character also connected with the water-storage of the TGR, the discharge of clear water from the reservoir and the dam, the scouring of river channel of the middle-lower Yangtze River, the fall of water level at the entrance of Three Outlets, the prolongation of the flow-break time of Three Outlets and the decrease of the water volume of Three Outlets. According to statistics, the number of the annual average flow-break days of the east branch of Songzi River was 150 days before 2002, while the number rose to 199 days in 2003-2010, a rise of 49 days. For Hudu River, the average flow-break days rose from 125 days to 152 days. The average flow-break days of the west and east branches of Ouchi River respectively rose from 241 days to 259 days and from 138 days to 186 days, a rise of 18 days and 48 days correspondingly. The water volume of Three Outlets decreases further with the extent of its flow-break time. On one hand, according to Table 1, the water volume of Three Outlets before the operation of the TGR decreases $179.4 \times 10^{8} \mathrm{~m}^{3}$ compared with the water volume after the operation under the similar water volume of Zhicheng Station, which weakens the replenishment ability of Three Outlets to Dongting Lake. On the other hand, the channel of the Yangtze River has been scoured. This lowers the datum plane of the riverbed from Chenglingji to Luoshan, and the water level of Chenglingji as well to a certain extent, which speeds up the water velocity from Four Rviers in low water level seasons and increases the water-storage volume of Dongting Lake. Finally, it will increase the outflow volume from Dongting Lake and improve the replenishment ability of Dongting Lake to Yangtze River.

\subsection{Changes of river-lake water exchange abilities in typical years}

In order to quantitatively analyze the change rule of water exchange abilities between Yangtze River and Dongting Lake in typical years from 1951 to 2010, water exchange coefficients between Yangtze River and Dongting Lake of 1994, 2006, 1960, 2007, 1999 and 2010 are calculated based on equation (1) as follows (Table 3). 
Table 3 Changes of the water exchange coefficient between Dongting Lake and Yangtze River in typical years in the past 60 years

\begin{tabular}{ccccccccc}
\hline $\begin{array}{c}\text { Dry } \\
\text { years }\end{array}$ & $\begin{array}{c}\text { Runoff of } \\
\text { Zhicheng } \\
\left(10^{8} \mathrm{~m}^{3}\right)\end{array}$ & $\begin{array}{c}\text { The coeffi- } \\
\text { cient }\end{array}$ & $\begin{array}{c}\text { Normal } \\
\text { years }\end{array}$ & $\begin{array}{c}\text { Runoff of } \\
\text { Zhicheng } \\
\left(10^{8} \mathrm{~m}^{3}\right)\end{array}$ & $\begin{array}{c}\text { The coef- } \\
\text { ficient }\end{array}$ & $\begin{array}{c}\text { Wet } \\
\text { years }\end{array}$ & $\begin{array}{c}\text { Runoff of } \\
\text { Zhicheng } \\
\left(10^{8} \mathrm{~m}^{3}\right)\end{array}$ & $\begin{array}{c}\text { The coef- } \\
\text { ficient }\end{array}$ \\
\hline 1994 & 3432.6 & 0.391 & 1960 & 4192.1 & 0.983 & 1999 & 4823.9 & 0.839 \\
2006 & 2930.6 & 0.288 & 2007 & 4180.3 & 0.815 & 2010 & 4824.0 & 0.631 \\
\hline
\end{tabular}

(1) The values of river-lake water exchange coefficients in typical years decrease in the order of the normal years (1960 and 2007) $>$ the wet years $(1999$ and 2010) $>$ the dry years (1994 and 2006). This indicates that, whether the TGR operates or not, the water exchange ability between Yangtze River and Dongting Lake is the strongest in the normal years and the lowest in the dry years. The reasons are as follows: In normal years, the outflow water from the TGR is regulated at a constant rate under different dispatching modes and the water volume from Four Rivers is relatively stable; in dry years, the river-lake exchange water volume is less compared with those in wet and normal years.

(2) River-lake water exchange coefficients in typical years before and after the operation of the TGR are all less than 1, which indicates the replenished water volume of Dongting Lake to Yangtze River dominates the water exchange in typical years in recent 60 years and the replenished water volume of Three Outlets to Dongting Lake obviously decreases. The main reason is that there is a distinct difference between river-lake water exchange volume before and after the operation of the TGR in typical years. According to Table 1, ratios of the runoff of Three Outlets to the runoff of Chenglingji were respectively 12.6\% in 1994 (the dry year), 24.7\% in 1960 (the normal year) and 27.1\% in 1999 (the wet year) before the operation of the TGR. The corresponding ratios of Four Rivers were $87.4 \%$ in 1994, 75.3\% in 1960 and $72.9 \%$ in 1999 . After the operation of the TGR, the corresponding ratios of Three Outlets decreased to $9.93 \%, 21.4 \%$ and $22.7 \%$ and the corresponding ratios of Four Rivers rose to $90.07 \%, 78.6 \%$ and $77.3 \%$. Based on the above analysis, whether the TGR operates or not, the river-lake water exchange volume is the direct factor influencing river-lake water exchange abilities.

(3) After the operation of the TGR, the river-lake water exchange coefficients in typical years all tend to decrease, which is consistent with its inter- and intra-change; but the change scope is different. The water exchange coefficient was the least in 2006 , which showed the water volume of Three Outlets decreased further and the water volume from Four Rivers was more, i.e. the replenishment ability of Dongting Lake to Yangtze River was stronger. This was the crux when the runoffs of Yichang Station and Zhicheng Station were the least, the runoff of Hankou Station in dry seasons in 2006 was more than the volume in normal years (Ou et al., 2012). It can be concluded from the above analysis, evolution characters of river-lake water exchange abilities in typical years reflect not only the complexity of the river-lake relation but also both the obvious randomness of and certain rules to follow in the water exchange volume between Yangtze River and Dongting Lake. 


\section{Responses of river-lake water exchange abilities to different modes of the TGR}

The TGR began to operate in June, 2003. The experimental impoundment to a water level of $175 \mathrm{~m}$ was started at the end of the flood in 2008. According to "the Management Scheme of the Three Gorges Reservoir", there are four periods when there is an obvious increase or decrease change of the outflow volume from the TGR. So, river-lake water exchange coefficients under all dispatching modes of the TGR are calculated based on equation (1) (Table 4) using the runoffs of Three Outlets and Chenglingji in corresponding periods.

Table 4 River-lake water exchange abilities under different dispatching modes of the TGR in typical years

\begin{tabular}{cccccccccc}
\hline $\begin{array}{c}\text { Dispatching } \\
\text { modes of the } \\
\text { TGR }\end{array}$ & $\begin{array}{c}\text { Dry } \\
\text { year }\end{array}$ & $\begin{array}{c}\text { Runoff } \\
\text { of } \\
\text { Zhicheng } \\
\left(10^{8} \mathrm{~m}^{3}\right)\end{array}$ & $\begin{array}{c}\text { The } \\
\text { coeffi- } \\
\text { cient }\end{array}$ & $\begin{array}{c}\text { Normal } \\
\text { year }\end{array}$ & $\begin{array}{c}\text { Runoff } \\
\text { of } \\
\text { Zhicheng } \\
\left(10^{8} \mathrm{~m}^{3}\right)\end{array}$ & $\begin{array}{c}\text { The } \\
\text { coeffi- } \\
\text { cient }\end{array}$ & $\begin{array}{c}\text { Wet } \\
\text { year }\end{array}$ & $\begin{array}{c}\text { Runoff of } \\
\text { Zhicheng } \\
\left(10^{8} \mathrm{~m}^{3}\right)\end{array}$ & $\begin{array}{c}\text { The } \\
\text { coeffi- } \\
\text { cient }\end{array}$ \\
\hline $\begin{array}{c}\text { Pre-discharge } \\
\text { dispatch }\end{array}$ & 1994 & 3432.6 & 0.561 & 1960 & 4192.1 & 1.251 & 1999 & 4823.9 & 0.818 \\
$\begin{array}{c}\text { Flood-storage } \\
\text { dispatch }\end{array}$ & 1994 & 3432.6 & 0.314 & 1960 & 4192.1 & 1.282 & 1999 & 4823.9 & 0.752 \\
$\begin{array}{c}\text { Water-storage } \\
\text { dispatch }\end{array}$ & 2006 & 2930.6 & 0.355 & 2007 & 4180.3 & 0.874 & 2010 & 4824.0 & 0.837 \\
$\begin{array}{c}\text { Water-supplement } \\
\text { dispatch }\end{array}$ & 1994 & 3432.6 & 0.492 & 1960 & 4192.1 & 1.535 & 1999 & 4823.9 & 0.641 \\
\hline
\end{tabular}

\subsection{Changes of river-lake water exchange abilities under the pre-discharge dispatch of the TGR in typical years}

The pre-discharge dispatch is the operation in order to control the flood, the water level of the TGR is decreased from $155 \mathrm{~m}$ to $145 \mathrm{~m}$ from 25 May to 10 June every year. The outflow volume from the TGR increases, which makes the flow of the middle Yangtze River increase by about $3800 \mathrm{~m}^{3} / \mathrm{s}$. Affected by these, runoffs of Three Outlets and Chenglingji from May to June in typical years slightly increase compared with that in the corresponding period before the operation of the TGR. However, river-lake water exchange coefficients all decrease to a certain extent (Table 4). It can be concluded from Table 4 that the coefficients from May to June in 2006, 2007 and 2010 after the operation of the TGR were all respectively less than the coefficients from May to June in 1994, 1960 and 1999. The order of the decrease scope is the normal year $>$ the wet year $>$ the dry year, which is consistent with the change in typical years. This indicates the river-lake water exchange coefficient is not very sensitive to the pre-discharge dispatch of the TGR in typical years, i.e. the dispatch does not profoundly influence the replenishment ability of Three Outlets to Dongting Lake. Though the water volume of Three Outlets slightly increases, Four Rivers in the Dongting area has entered into the flood season and the ratio of the inflow volume into the lake to the outflow volume out of the lake is $68.2 \%$ in the pre-discharge dispatch period of the TGR. So the replenishment ability of Three Outlets to Dongting Lake is weaker and the replenishment ability of Dongting Lake to Yangtze River is stronger under this dispatch. From the perspective 
of the flood preventing and disaster reduction, if there is no deluge in the upper Yangtze River, the river-lake water exchange process under the pre-discharge dispatch is very helpful to weaken the peak flood of Four Rivers in the Dongting Lake area. However, if there are deluges both in the upper Yangtze River and in Four Rivers at the same time, this process will increase the probability of the flood in the lake area.

\subsection{Changes of river-lake water exchange abilities under the flood-storage dispatch of the TGR in typical years}

In order to regulate the flood and cut the flood peak, the TGR implements the flood-storage dispatch, i.e. the flood-control limited water level of the TGR is set as $145 \mathrm{~m}$. The water level can exceed $145 \mathrm{~m}$ during the worse flood and decreases to $145 \mathrm{~m}$ after the flood crest. Affected by these, there are some changes of the river-lake water exchange coefficient too (Table 4). Every coefficient obviously increases in wet and dry years after the operation of the TGR. The reasons are that the outflow flood volume from the TGR under the flood-storage dispatch is regulated at a constant rate which reduces the difference between the water volumes of Three Outlets and from Four Rivers. The coefficient slightly decreases in normal years and its decrease scope is 0.408 . This indicates the replenishment ability of Dongting Lake to Yangtze River improves because the flood volume from Four Rivers is much more than the volume of Three Outlets. In the mass, under this dispatch the TGR stores much floods, equalizes the outflow flood volume and cuts down the flow of the peak flood. The exchange process is very helpful to the flood-discharge safety and the reduction of the flood risk for Dongting Lake and Yangtze River.

\subsection{Changes of river-lake water exchange abilities under the water-storage dispatch of the TGR in typical years}

According to "The Management Scheme of the Three Gorges Reservoir", the water level of the TGR will rise from $145 \mathrm{~m}$ to $175 \mathrm{~m}$ from 15 September to 31 October under the water-storage dispatch. The corresponding stored water volume is $221.5 \times 10^{8} \mathrm{~m}^{3}$ and the daily outflow water volume from the reservoir decreases by $5500 \mathrm{~m}^{3} / \mathrm{s}$, which makes the flow of the Yangtze River above Yichang slightly decrease compared with the natural volume before the operation. Affected by these, the water volume of Three Outlets decreases to various degrees, which causes the river-lake water exchange coefficient diminishing correspondingly in typical years (Table 4), the biggest decrease scope of which is in 2007 (0.806), i.e., the normal year. The main reason are as follows: before and after the operation of the TGR in normal years, the difference in the ratio of the inflow volume into the lake to the water volume of Chenglingji between Three Outlets and Four Rivers is bigger than that in dry and wet years. Before the operation of the TGR, the ratios of the inflow volume into the lake of Three Outlets and Four Rivers to the outflow volume out of the lake of Chenglingji are respectively $37.5 \%$ and $62.5 \%$ from September to October in 1960, which proves that the replenishment ability of Three Outlets to Dongting Lake is stronger; after the operation, the corresponding ratios of Three Outlets and Four Rivers are 19.6\% and 80.4\% in 2007, which indicates the replenishment ability of Three Outlets to Dongting Lake becomes weaker because the water volume of Three Outlets decreases under the water-storage dispatch. So, from the perspective of the water resources amount, if there are droughts both in Yangtze 
River and in Dongting Lake at the same time, the river-lake water exchange character under this dispatch of the TGR will cause the disadvantage to the water resources development and utilization of the river-lake area. For example, there was an autumn-winter drought in recent 60 years both in the middle-lower Yangtze River area and in the Dongting Lake area in 2011 for the water shortage ${ }^{4}$.

\subsection{Changes of river-lake water exchange abilities under the water-supplement dis- patch of the TGR in typical years}

In order to satisfy the demand of the comprehensive use of the TGR, the water level of the reservoir drops from $175 \mathrm{~m}$ to $155 \mathrm{~m}$ step by step and the outflow water volume is controlled to be $5800 \mathrm{~m}^{3} / \mathrm{s}$ to keep the firm power of the Three Gorges Hydropower Station in dry seasons (from January to March). The flow of Yangtze River above Yichang increases by $1000-2000 \mathrm{~m}^{3} / \mathrm{s}$ compared with that before the operation of the TGR, that is, the reservoir under the water-supplement dispatch supplements water to the riverway of the middle-lower Yangtze River in dry seasons. Affected by these, though the outflow volumes from the reservoir in typical years all increase, the river-lake water exchange coefficients still tend to decrease (Table 4). The main reasons are as follows: the water level of Zhicheng under the water-supplement dispatch decreases $0.38 \mathrm{~m}$ compared with the annual average before the operation of the TGR (Ou et al., 2012), which makes Songzikou, Ouchikou and Taipingkou enter into the flow-break in advance one by one and the water volume of Three Outlets decrease. This explains the river-lake water exchange ability is not sensitive to the water-supplement dispatch of the TGR in typical years. The river-lake water exchange coefficient was the least in 2010 (0.061) among those in three typical years after the operation of the TGR, which shows the water volume of Three Outlets from January to March in 2010 was the least and the replenishment ability of Dongting Lake to Yangtze River was the strongest. The main reasons are as follows: after the TGR stored the flood five times in the flood season (from May to August) in 2010 (accumulated flood volume stored by the TGR was $235 \times 10^{8} \mathrm{~m}^{3}$ ) (Zheng, 2011), Yangtze River entered into the dry season in advance in late September which was still in the wet season in normal years. Three Outlets broke flow in advance and its flow-break time prolonged, which made the water volume of Three Outlets very little. While the Chenglingji section was scoured and the gradient of the water surface decreased, which sped the water flow of Three Outlets and increased the inflow volume into Yangtze River from Dongting Lake. From the perspective of the water resources, this exchange process is helpful to the water resources development and utilization in Yangtze River above Luoshan Station and will cause some disadvantages to the water resources development and utilization in the north Dongting Lake area and in the tail of the Four Rivers area.

\section{Conclusions}

(1) The water exchange ability between Yangtze River and Dongting Lake is represented

\footnotetext{
${ }^{4}$ Li Jingbao, Li Yudan, Wang Keying et al. "The Influence of the Operation of the TGR on the Water Resources Development and Utilization in the North Dongting Lake Area”. Research Report of Hunan Normal University, 2012.
} 
as the complementary relation between Yangtze River and Dongting Lake, i.e. the replenishment process of Three Outlets to Dongting Lake and the replenishment process of Dongting Lake to Yangtze River. So the ability reflects the river-lake hydrologic relation, the connectivity of the river-lake water systems and the reciprocity between Yangtze River and Dongting Lake. Therefore, it is very important to analyze the evolution characters of river-lake water exchange abilities and its impact factors from different time scales for keeping the connectivity of the river-lake water systems, the flood control and disaster reduction, the water resources development and utilization.

(2) The evolution characters of river-lake water exchange abilities from different time scales are as follows: the replenishment ability of Three Outlets to Dongting Lake is stronger in autumn and the replenishment ability of Dongting Lake to Yangtze River is stronger in spring. The replenishment ability of Three Outlets to Dongting Lake was stronger in 1951-1958 and in 1959-1968. The replenishment ability of Dongting Lake to Yangtze River became stronger in 2003-2010. In typical years under different dispatching modes of the TGR, the water volume of Three Outlets decreases and the replenishment ability of Three Outlets to Dongting Lake becomes weaker; the replenishment ability of Dongting Lake to Yangtze River obviously improves because the water volume from Four Rivers dominates the inflow volume into the lake.

(3) From both the perspective of the flood preventing and disaster reduction, and the perspective of the water resources development and utilization, in the evolution process of river-lake water exchange abilities the distributary capacity of Three Outlets becomes weaker in the main flood season, which relieves the flood pressure and decreases the flood probability in the Dongting Lake area to a certain extent; the replenishment ability of Dongting Lake to Yangtze River becomes stronger in dry seasons, which is very helpful to the water resources development and utilization in Yangtze River above Luoshan Station and will cause some disadvantages to the water resources development and utilization in the north Dongting Lake area and in the tail of the Four Rivers area.

(4) There is a complex hydrological and hydraulic exchange process between Dongting Lake and Yangtze River under the interaction of the river-lake hydrodynamic force. Affected synthetically by the runoff fluctuation in the basin and the disturbance of the hydraulic project, the evolution characters of the water exchange ability between Dongting Lake and Yangtze River in different time scales are generally changed with the variation of the water exchange amount between them. So there is an in-line growth or decline relation between river-lake water exchange abilities and the river-lake water exchange amount. As far as the river-lake hydraulic relation is concerned, the value of the river-lake water exchange coefficient or the exchange ability is mainly related with the water volume of Three Outlets both before and after the operation of the TGR.

\section{References}

Betts H, Makar S, Clark S, 2008. Practical Hydroinformatics. Berlin and Heidelberg: Springer, 479-493.

Guo Hua, Zhang Qi, 2011. Changes in hydrological interactions of the Yangtze River and the Poyang Lake in

China during 1957-2008. Acta Geographica Sinica, 66(5): 609-618. (in Chinese)

$\mathrm{Hu}$ Xinlin, 2000. Analysis of time-space distribution regulation and evolution tendency of runoff of main rivers in 
Gansu Province. Advance in Earth Sciences, 15(5): 516-521. (in Chinese)

Li Jingbao, Dai Yong, Yin Rixin et al., 2013. Effects of Three Gorges Reservoir impoundment on the wetland ecosystem service value of Dongting Lake, south-central China. Chinese Journal of Applied Ecology, 24(3): 809-817. (in Chinese)

Li Jingbao, Liu Xiaoqing, 1993. The influence to Dongting Lake water of Jingjiang River truncation and construction of the Gezhouba Dam. Journal of Natural Science of Hunan Normal University, 16(4): 63-70. (in Chinese)

Li Jingbao, Yin Hui, Chang Jiang et al., 2009. Sedimentation effects of the Dongting Lake area. Journal of Geographical Sciences, 19(3): 287-298.

Lu Jinyou, Luo Hengkai, 1999. Preliminary analysis on variation of the relation between Yangtze River and Dongting Lake. Yangtze River, 30(4): 24-26. (in Chinese)

Ma Yuanxu, Lai Hongzhou, 2005. Research on the variations of the water and sediment for recent 50 years in the Jingjiang River and Dongting Lake area. Research of Soil and Water Conservation, 12(4): 103-106. (in Chinese)

Mikhailov V N, Korotaev V N, Mikhailova M V et al., 2001. Hydrological regime and morphodynamics of the Yangtze River mouth area. Water Resources, 28(4): 351-363.

Ou Chaomin, Li Jingbao, Zhang Zhaoqing et al., 2012. Effects of the dispatch modes of the Three Gorges Reservoir on the water regimes in the Dongting Lake area in typical years. Journal of Geographical Sciences, 22(4): 594-608.

Ou Chaomin, Zhuang Wei, 2012. Evolution trend of hydrologic and sediment regime in Jingjiang River and Dongting Lake. Resources and Environment in the Yangtze Basin, 21(11): 1382-1388. (in Chinese)

Qu Geng, Tang Feng, Liu Xiaobin, 2007. Variations and effects on water and sediment in the Jingjiang River Three Outlets and Dongting Lake. Journal of Water Resources and Water Engineering, 18(3): 94-100. (in Chinese)

Sun Zhandong, Huang Qun, Christian O et al., 2012. Impacts and implications of major changes caused by the Three Gorges Dam in the middle reaches of the Yangtze River, China. Water Resources Management, 26(12): 3367-3378.

Wu Jinglu, Zeng Haiao, Yu Hong et al., 2012. Water and sediment quality in lakes along the middle and lower reaches of the Yangtze River, China. Water Resources Management, 26(12): 3601-3618.

Zhang J C, DeAngelis D L, Zhuang J Y, 2011. Theory and Practice of Soil Loss Control in Eastern China. New York: Springer, 3-27.

Zhang Qiang, Vijay P Singh, Xiaohong Chen, 2012. Influence of Three Gorges Dam on streamflow and sediment load of middle Yangtze River, China. Stochastic Environmental and Risk Assessment, 26(4): 569-579.

Zheng Shouren, 2011. Some considerations on related problems in pilot impoundment of TGP at design water level of $175 \mathrm{~m}$. Yangtze River, 42(13): 1-7. (in Chinese)

Zhong Zhiyu, Hu Weizhong, 2008. On relation of river and lake. Yangtze River, 39(1): 20-23. (in Chinese) 